\title{
Motility of spermatozoa at surfaces
}

\author{
D. M. Woolley \\ Department of Physiology, School of Medical Sciences, University of Bristol, Bristol BS8 1TD, UK
}

\begin{abstract}
The hydrodynamic basis for the accumulation of spermatozoa at surfaces has been investigated. The general conclusion is that when spermatozoa arrive at a surface, they will remain there if the vector of the time-averaged thrust is directed towards that surface. This can arise in two basic ways. First, consider spermatozoa that maintain a three-dimensional waveform and roll (spin) as they progress: in this case, it is argued that the conical (rather than cylindrical) shape of the flagellar envelope will establish the direction-of-thrust necessary for capture by the surface. (Additional findings, for spermatozoa of this type, are that the swim-trajectory is curved and that the direction of its curvature reveals the roll-direction of the cell.) Second, consider spermatozoa that maintain a strictly two-dimensional waveform at the surface: in this case, spermatozoa can be captured because the planeof-flattening of the sperm head is tilted slightly relative to the plane of the flagellar beat. The sperm head is acting as a hydrofoil and, in one orientation only, it comes
\end{abstract}

to exert a pressure against the surface. (This pressure may possibly, in vivo, aid the penetration of the zona pellucida.) The hydrofoil action of sperm heads may explain any bias in the circling direction of spermatozoa that execute two-dimensional waves at surfaces. Finally, a more complex phenomenon is where interaction of the spermatozoa with the surface appears to induce a threedimensional to two-dimensional conversion of the flagellar wave (thus permitting the hydrofoil effect described). This is characteristic of sperm with 'twisted planar' rather than helical waves. In mammalian spermatozoa, approximately half the beat cycle is planar and the other half generates a pattern of torque causing the head to roll clockwise (seen from ahead), producing a torsion of the neck region of the flagellum. It is the gradual suppression of this torsion, by either impedance at the solid boundary or by raised viscosity, that converts the 'twisted planar' shape into a planar wave.

\section{Introduction}

In general, freely motile spermatozoa tend to accumulate at surfaces. Rothschild (1963) was the first to show this quantitatively, for bull spermatozoa. He concluded that the spermatozoa were held at a liquid-solid boundary by a 'hydrodynamic interaction' rather than by chemical interactions, adhesiveness or through gravitational effects (sedimentation, geotaxis). Whatever the mechanism, the physiological effect of the accumulation might be to promote contact between the spermatozoa and the surface of the egg or its investments. Dewitz (1886) was probably the first to recognize that sperm movement on the surface of the Periplanetus egg closely resembled that on the surface of a glass slide. The present paper is a further investigation of Rothschild's 'hydrodynamic interaction': it provides new evidence to explain the behaviour of spermatozoa as they encounter the boundaries of the fluid in which they swim.

The study was started when it was noticed that mouse spermatozoa propagating planar waves always circle in the same direction when swimming at the surface of a viscous medium. This extremely non-random pattern

Email: d.m.woolley@bristol.ac.uk will be attributed to a tilt in the orientation of the head with respect to the plane of the flagellar wave. The second part of the study has concentrated on the nature of the three-dimensional wave that develops when mammalian spermatozoa are remote from surfaces, the aim being to specify what happens in its conversion to two-dimensionality. This has produced a description of the waveform dynamics as 'twisted planar' rather than helical. Finally, it will be shown that spermatozoa executing three-dimensional waves, whether 'twisted planar' or helical, may also accumulate at surfaces and follow circular tracks, as depicted by Rothschild (1953); however, in this instance the factors responsible are thought to be the shape of the flagellar envelope and the rolling motion of the cell, respectively.

\section{Materials and Methods}

Spermatozoa were obtained from mice (CD1 strain), rats (Wistar) and chinchillas by puncturing the cauda epididymidis, post mortem, and suspending the cells

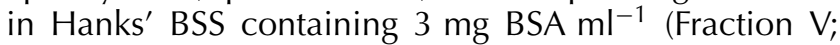
Sigma, St Louis, MO), at room temperature. Ram semen was obtained by electro-ejaculation. Spermatozoa from 

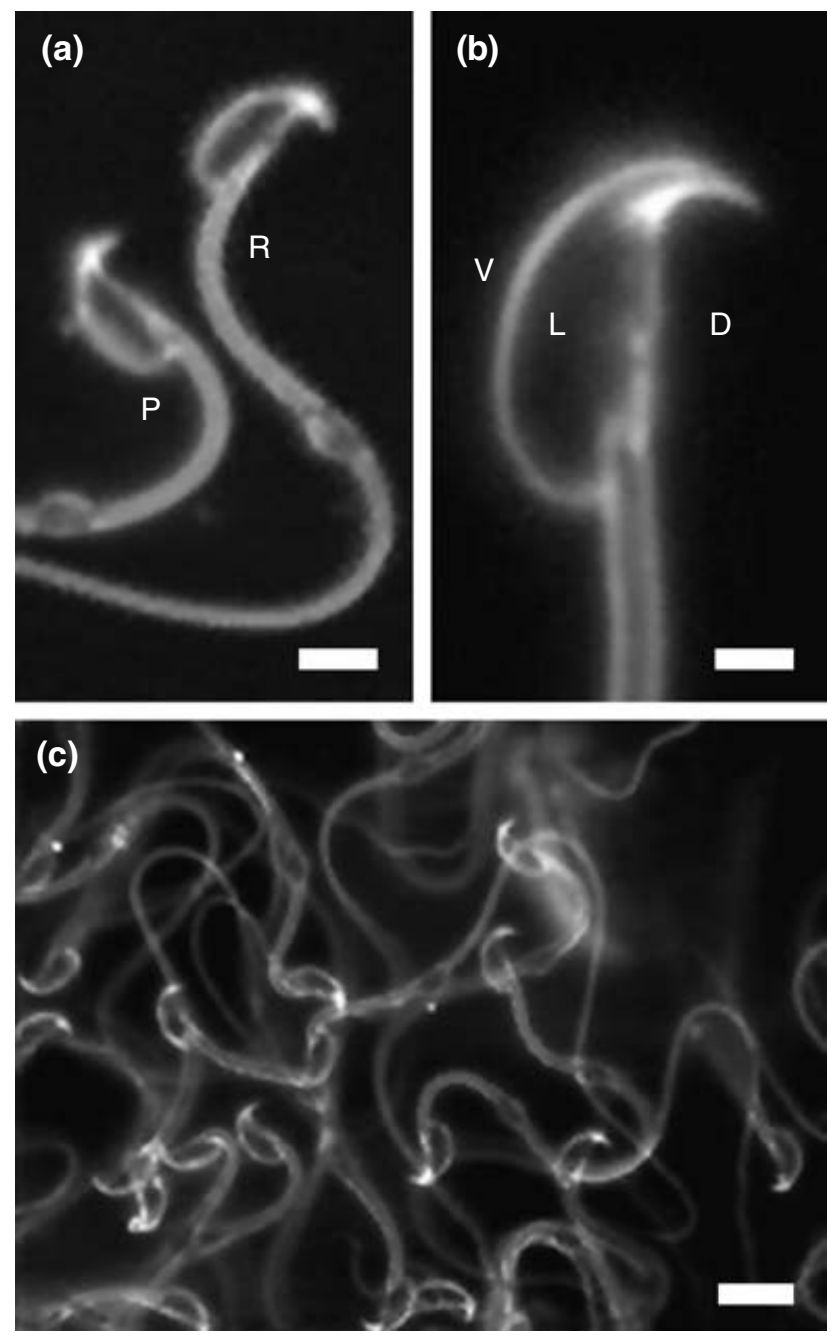

Fig. 1. Mouse spermatozoa. (a) Principal (P) and reverse (R) bends defined in relation to the asymmetrical structure of the sperm head. (b) Ventral (V) and dorsal (D) edges and the left surface (L) of the sperm head. The nucleus has a posterior lobe lying alongside the neck and proximal mid-piece. (c) Movement in viscous saline, immediately below the coverslip. All spermatozoa that have normal morphology and remain at the coverslip present their left sides to the glass. Scale bars represent (a) 5, (b) 2 and (c) $10 \mu \mathrm{m}$.

various birds, eels, Xenopus and sea urchins were obtained as described by Vernon and Woolley (1999), Woolley (1997), Bernardini et al. (1988) and Woolley and Vernon (2001), respectively. A slide chamber about $80 \mu \mathrm{m}$ deep (that is, supported coverslip) was prepared containing a droplet $(25 \mu \mathrm{l})$ of Hanks' BSS containing BSA and also (in most of the work) $2 \%(\mathrm{w} / \mathrm{v})$ methyl cellulose (Sigma, three molecular weight ranges, cat. nos. M0262, M0387, M0512) so as to raise the viscosity to, nominally, 400,1500 or $4000 \mathrm{cP}(0.4,1.5$ or 4.0 Pa s). In some trials the droplet was positioned over the boundary between the clear slide and its frosted (sandblasted) end, so that sperm movement against an irregular glass surface could be observed. The sperm suspension was then run into the chamber so as to form an interface with this droplet. The observations were made at room temperature $\left(22-24^{\circ} \mathrm{C}\right)$. The motility of spermatozoa that swam into the droplet is described in this study. The Leitz Ortholux II microscope was fitted with a $100 \mathrm{~W}$ quartz-iodide lamp, a heat filter and a UV barrier filter; synchronized stroboscopic illumination was also used on some occasions (Chadwick-Helmuth model 8440). Illumination was through an oil immersion darkfield condenser or a phase-contrast (Heine) condenser. The motility was recorded on sVHS videotape using a standard $50 \mathrm{~Hz} \mathrm{~B} \mathrm{\&} \mathrm{W} \mathrm{(CCD)} \mathrm{camera} \mathrm{and} \mathrm{a} \mathrm{Panasonic}$ (AG7350) VCR linked to a For.A videotimer (model VTG33F). In some cases a $200 \mathrm{~Hz}$ CCD system was used, involving a modified CCD camera (Pulnix PE2105), an interface controller (model CCU1; Brian Reece Scientific Ltd, Newbury) and synchronized stroboscope illumination.

For scanning electron microscopy, mouse and rat spermatozoa were suspended in Hanks' BSS, washed by pelleting and resuspension, and fixed in suspension by adding an equal volume of $4 \%(\mathrm{v} / \mathrm{v})$ glutaraldehyde in $0.2 \mathrm{~mol}$ cacodylate buffer $\mathrm{I}^{-1}$ containing $0.2 \mathrm{~mol}$ sucrose $\mathrm{I}^{-1}$. After $1 \mathrm{~h}$, droplets of fixed suspension were allowed to stand on poly-lysine-coated coverslips for $30 \mathrm{~min}$. The coverslips were drained, rinsed in $0.2 \mathrm{~mol}$ cacodylate buffer $\mathrm{I}^{-1}$, dehydrated in alcohol, taken to anhydrous acetone, critical point-dried, sputter-coated with gold and viewed in a Philips 501B scanning electron microscope.

Transmission electron micrographs were prepared by a standard method (Woolley, 1977), from thin sections of spermatozoa fixed in situ in the cauda epididymidis.

\section{Results}

Movement at the surface when the flagellar wave is two-dimensional (mammals)

For rodent spermatozoa with falciform heads (mouse, rat), flagellar bends of opposite direction (principal $(\mathrm{P})$, reverse $(R)$ ) have been defined by reference to the head asymmetry (Fig. 1a) (Woolley, 1977). Retzius (1909) and Friend (1936) used 'dorsal' and 'ventral' for the two edges of the sperm head. Therefore, the two broad surfaces of the head must be called 'left' and 'right', as shown (Fig. 1b).

In saline of viscosities 1.5 and $4.0 \mathrm{~Pa} \mathrm{~s}$, mouse spermatozoa of normal morphology always follow an anti-clockwise path when swimming parallel with and close to the coverslip. Their paths are circular because the angle achieved by the principal bend exceeds that of the reverse bend. The reason why all the circular movements are anti-clockwise (an observation based on thousands of examples) is that spermatozoa of normal structure only become stabilized at the coverslip if the left side of the head faces the glass surface (Fig. 1c). This 'left-side rule' 

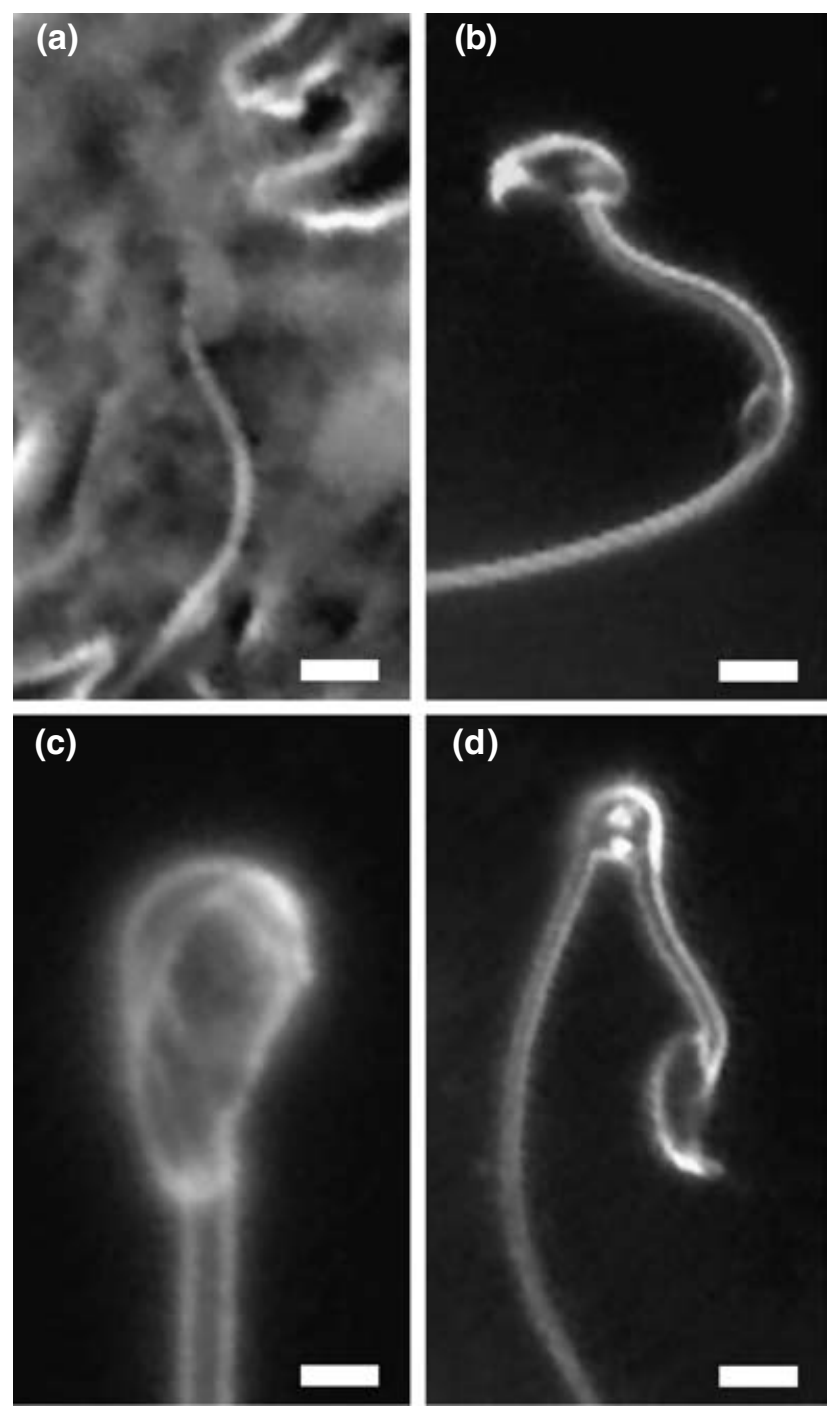

Fig. 2. Mouse spermatozoa. (a) The spermatozoon is visible even though it is swimming on a frosted (sandblasted) slide surface; contact with irregular projections of the surface sometimes caused the cells to roll through $180^{\circ}$, whereupon they immediately rose from the surface. (b) Spermatozoon showing the 'partial dislocation at the neck' defect; most of these stabilized with the right surface of the head against the glass. (c) Spermatozoon showing the 'reversed head' defect, in which an extreme principal bend loops around the curvature of the head; motility is retained. (d) Spermatozoon showing the 'kinked tail' defect due to swelling of the cytoplasmic droplet (at top of figure); motility is retained. Scale bars represent (a,b,d) 5 and (c) $2 \mu \mathrm{m}$.

also applied at the slide surface (where the right side of the head now faces the observer and the motion is seen as clockwise). The rule applies also to spermatozoa at the upper surface when no coverslip is present.

This 'preferential capture' by the surface was observed directly. Spermatozoa arriving at the coverslip rightsurface-uppermost did not roll over but left the surface within one or two flagellar beats. On the surface of
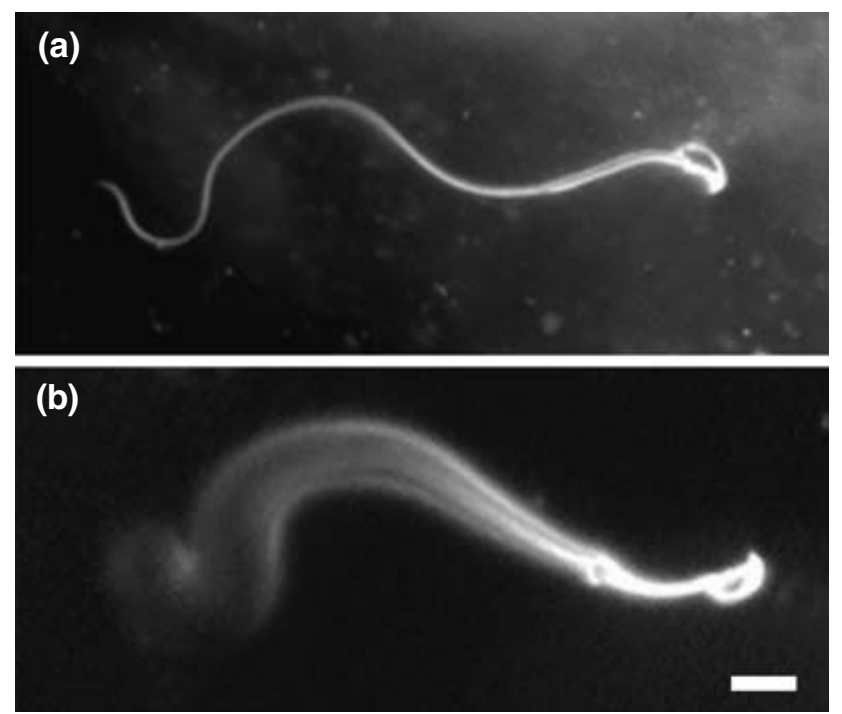

Fig. 3. Mouse spermatozoa swimming at the coverslip in albuminsaline (without methyl cellulose). Exposure time of strobe was $15 \mu \mathrm{s}$. (a) Stabilization at the surface, with a two-dimensional wave in the plane of the surface, occurs when the left surface of the head is against the glass. (b) If the right surface of the head stabilizes briefly, the flagellum projects deeper into the fluid. Scale bar represents $10 \mu \mathrm{m}$.

a frosted glass slide, the rule still applied and the sperm stabilized, and remained left-surface-downwards, for up to about 100 beat cycles (Fig. 2a). However, when a collision with a rough surface projection (or asperity) caused a spermatozoon to roll over (witnessed six times), it immediately rose from the surface and swam to the coverslip, where it stabilized, now left surface uppermost. Thus, spermatozoa move between the surfaces of the chamber until, by chance, the left surface of the head faces the glass: thereafter they do not leave that surface.

The following results constitute the evidence that 'preferential capture' is due to some anatomical feature of the head and, specifically, to the angle at which the surfaces of the sperm head are presented to the fluid as the cell moves forward. (i) When there is a rare, partial dislocation at the neck region (Fig. 2b), the 'left-side rule' for 'preferential capture' is reversed. Of 60 examples, 59 stabilized right-side-against the glass; these had planar waveforms, indicating that the flagellum could become planar whichever side of it was against the surface. (ii) For another abnormality, 'reversed-head' (Fig. 2c), only $75 \%(n=100)$ of specimens obeyed the 'left-side rule' for capture. (iii) For the 'kinked-mid-piece' abnormality (Fig. 2d), which causes the head to project sideways, 13 of 18 examples did not follow the 'leftside rule'. (iv) Spermatozoa with other, very rare, head abnormalities did not conform to the 'left-side rule'. (v) In standard saline (no methyl cellulose), some spermatozoa were found to disobey the 'left-side rule', but in these 

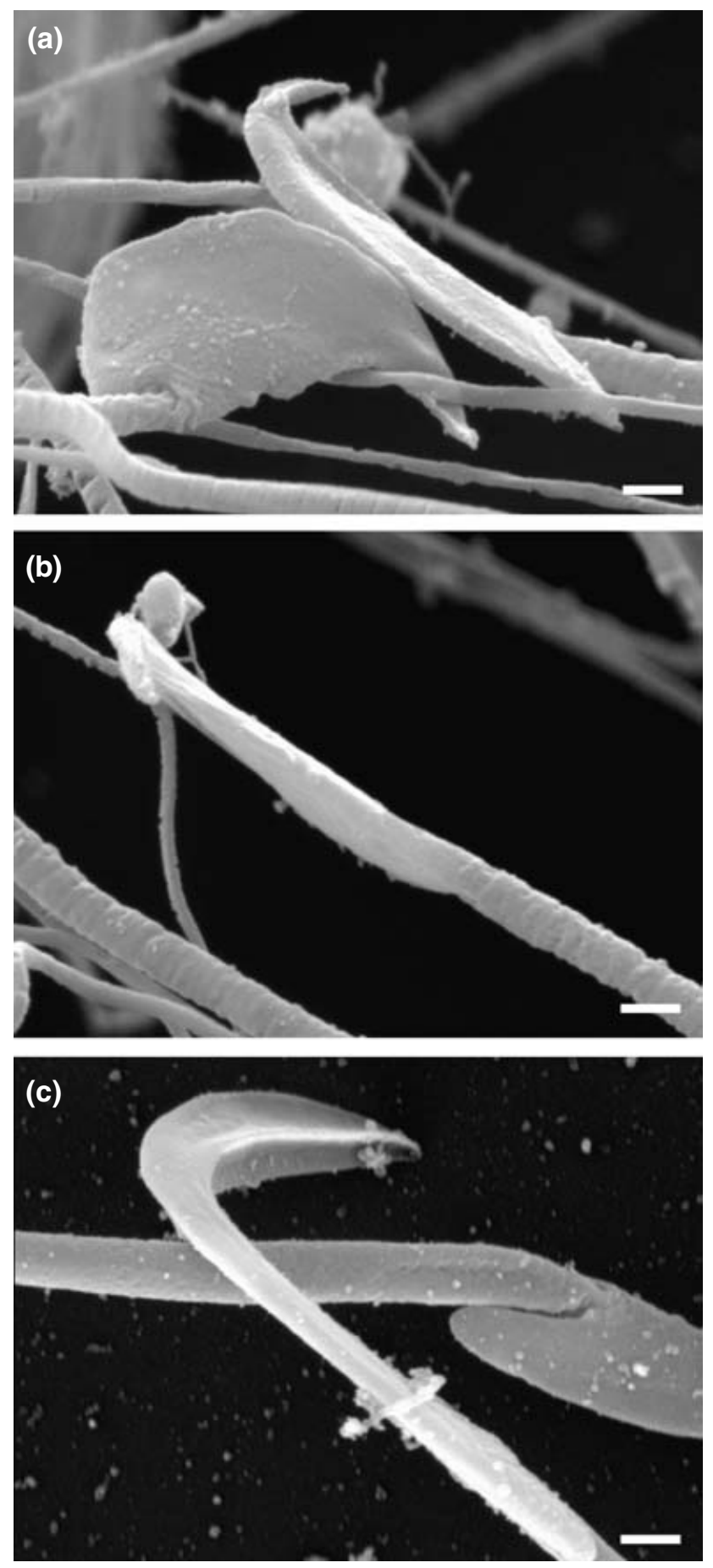

Fig. 4. Scanning electron micrographs. (a) Mouse spermatozoa. The sperm head to the left-of-centre has its left surface towards the viewer (compare with Fig. 1b) and the posterior lobe of the nucleus lies slightly deeper than the adjacent mid-piece. The sperm head to the right-of-centre is viewed from a position nearly in line with its ventral edge: the plane of flattening of the head is angled towards the flagellum, perhaps to an exaggerated degree in this specimen; the hook of this sperm head appears to project out of the left surface. (b) A mouse spermatozoon, viewed from a position nearly in line with its dorsal edge. A head-flagellum tilt is not apparent in this specimen but the hook of the head can be seen to project out of instances only the head stabilized at the coverslip, with the flagellum angled downwards (Fig. 3). (vi) Scanning electron micrographs taken from viewpoints close to the plane of flattening of the head indicated that the angle between the left surface of the head and the plane of the flagellar bend was typically less than $180^{\circ}$, that is, the head plane was inclined to the beat plane (Fig. 4a). In addition, note that the hooked part of the head curved out of the head plane in the way shown (Fig. 4a,b). (vii) Transverse sections through the neck region of 31 spermatozoa showed that in seven spermatozoa the head and flagellum were co-planar, whereas in 20 other spermatozoa the head was inclined in the direction described above (Fig. 5a) and in four spermatozoa it was inclined in the opposite direction. The observed ratio, 20:4, is significantly different from 12:12, the expectation for co-planarity (chi-squared $=10.7, P<0.01$ ).

For rat spermatozoa, most adopted planar waveforms at viscosity $1.5 \mathrm{~Pa} \mathrm{~s}$ and all did so at 4.0 Pa s. The principal and reverse bends reached similar angles, so the progression paths tended to be straight. In a sample of 44 spermatozoa, 43 conformed to the left-side rule, thereby indicating the same inclination of the head as observed in mouse spermatozoa. However, this finding could not be confirmed in scanning electron micrographs, although a curving inclination of the hooked portion was again observed, more prominently than that in mice (Fig. 4c). However, in a series of transverse sections through the neck region (30 cells), 20 showed the inclination as observed in mice, five had the opposite inclination and five were co-planar (Fig. 5b). The ratio 20:5 is significantly different from expectation (chisquared $=9.0, P<0.01$ ).

Chinchilla sperm heads are asymmetrical, although not hook-shaped (Fig. 6a). Under the same high viscosity conditions, very few spermatozoa ever adopted a twodimensional beat, even after $5 \mathrm{~h}$. Only nine such spermatozoa were found, in a search of many hundreds, and all nine followed clockwise circular paths at the coverslip and presented the same surface of the head to the glass, a fact that is unlikely to have occurred by chance $(P<0.01)$. This finding indicates that the planeof-flattening of the head is inclined to the plane of the beat. Further evidence for this is in the next section.

Ram sperm heads are symmetrical, that is the left and right surfaces are indistinguishable (Fig. 6b).

the left surface. (c) Rat spermatozoa. The spermatozoon in the background shows the features of the posterior head (right surface) and proximal mid-piece. The sperm head in the foreground is viewed from a position in line with its ventral edge; this viewpoint shows the pronounced projection (or twist) of the hook out of the left surface of the head. The disposition of the hook is similar in the two species and means that the dorsal edge of the head presents an angled surface to the fluid as the flagellar stroke moves from a principal bend to a reverse bend. Scale bars represent $1 \mu \mathrm{m}$. 

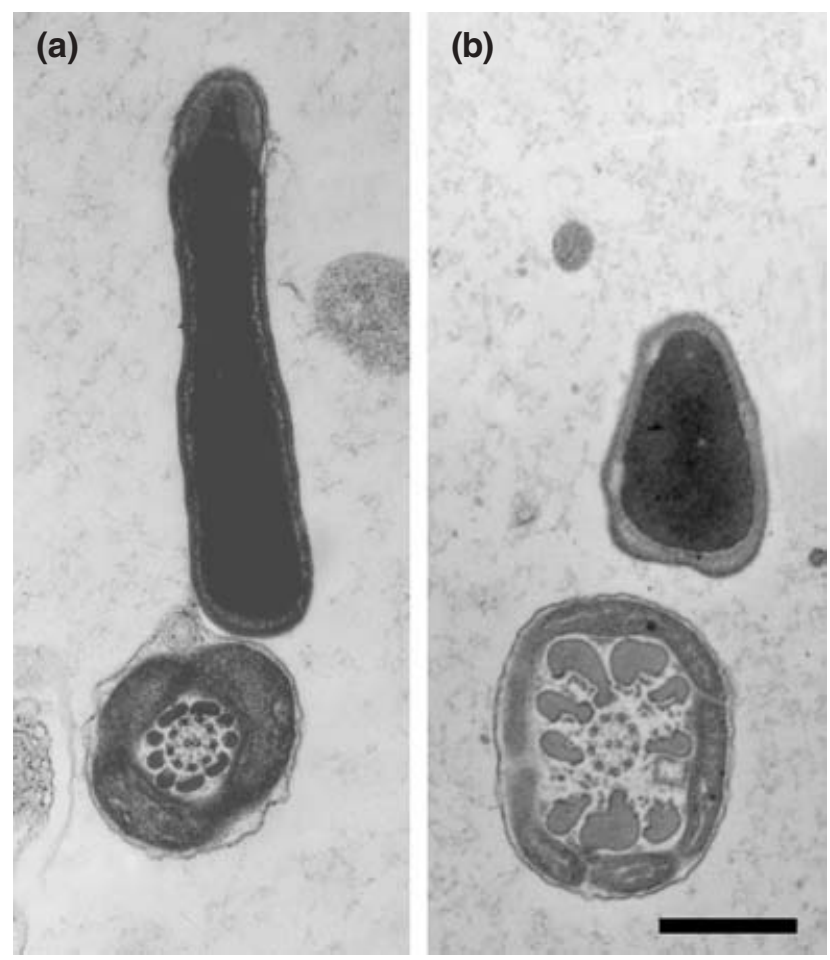

Fig. 5. Transmission electron micrographs of thin sections through the posterior nuclear lobe of (a) a mouse and (b) a rat spermatozoon. Higher magnification views (not shown) leave no doubt that the axonemal handedness in these images is clockwise, that is they are being viewed from base-to-tip. The slight displacement of the flagellum towards the left side of the plane-of-flattening-ofthe-head is consistent with the tilt direction between head and flagellum shown in Fig. 4a and inferred from the behaviour of living spermatozoa at surfaces. Scale bar represents $0.5 \mu \mathrm{m}$.

They were observed in saline of viscosity 1.5 Pa s. All spermatozoa observed under these conditions adopted a two-dimensional beat and swam at the surfaces. Some showed no beat asymmetry, although in most it occurred to a slight degree. Correspondingly, the swimming paths were either straight or were circular and of large radius. All the circular paths of large radius at the coverslip were clockwise. (A few erratically moving cells with extreme beat asymmetry were found moving either anti-clockwise or clockwise.)

\section{Three-dimensional waves and the transition to two-dimensionality at the surface (mammalian spermatozoa)}

When not close to surfaces, the flagellar waveform of active mammalian spermatozoa is three-dimensional. From the above account, the three-dimensional to twodimensional transition at the surface of a viscous medium may occur readily (mouse, ram), less readily (rat) or only rarely (chinchilla); in addition, the transition is promoted by a higher degree of viscosity (rat). In this study, a new
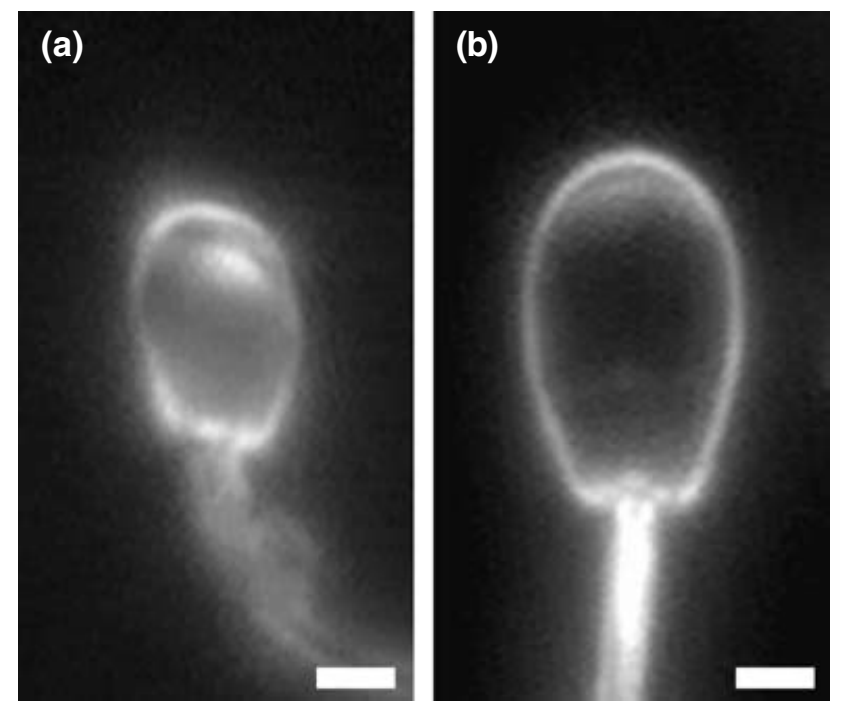

Fig. 6. (a) A chinchilla spermatozoon, swimming with a planar waveform against the coverslip, in viscous saline. The slight but recognizable head asymmetry in this species made it possible to conclude that all such spermatozoa had stabilized with the same surface against the glass (preferential capture). (b) A ram spermatozoon, in the same conditions. The head is symmetrical in this species: preferential capture cannot therefore be confirmed directly but has been inferred from the uniform circling direction of those cells with asymmetric flagellar beating. Scale bars represent $2 \mu \mathrm{m}$.

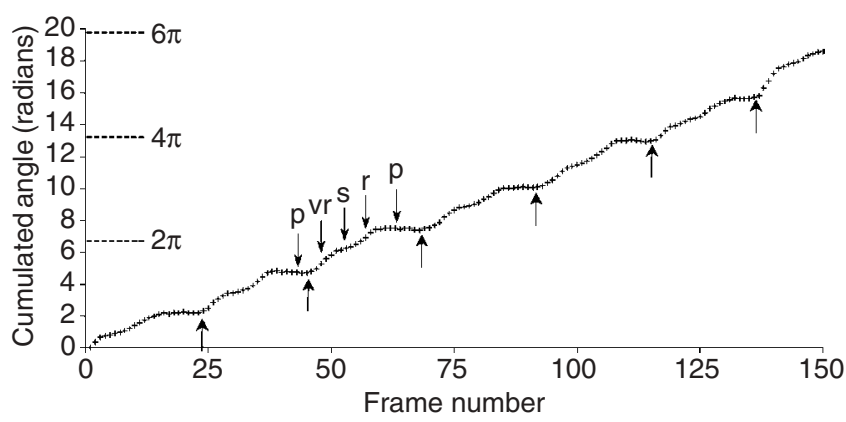

Fig. 7. The rotation (spin) of a mouse spermatozoon, loosely attached to the coverslip, during $0.75 \mathrm{~s}$. The sperm head was imaged as a line, the angle of which was measured in successive video fields (that is, every $5 \mathrm{~ms}$ ). The accumulated angle is plotted as the ordinate: it can be seen that the cell made three complete revolutions ( $2 \pi, 4 \pi, 6 \pi$ radians). From out-of-focus images of the proximal flagellum, it could be seen that the flagellum performed almost seven beat cycles during this period (indicated by the upward-pointing arrows). The pattern in the rate of angular change consists of four phases: pause $(p)$, very rapid (vr), slow (s) and rapid ( $r$ ) (indicated by downward-pointing arrows).

attempt has been made to show how, in the first place, the three-dimensionality is generated in order to provide a basis for explaining the transition. Several types of evidence have contributed to a consistent picture. 

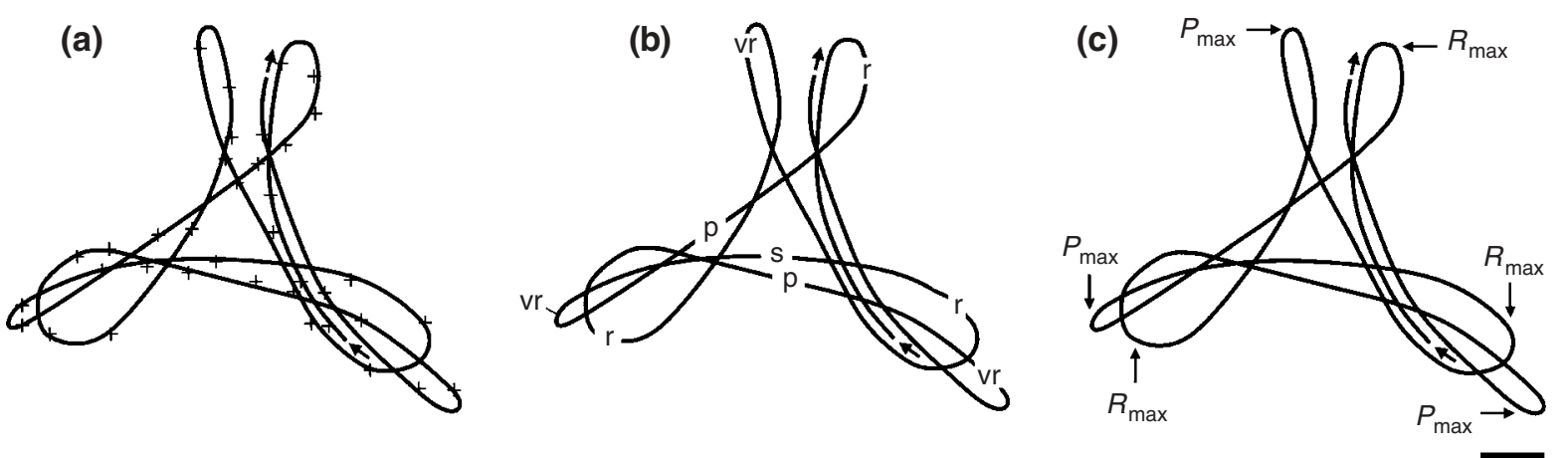

Fig. 8. The 'flagelloid curve' or track followed by a point on the mid-piece of a mouse spermatozoon when 'swimming' upwards against the coverslip (as seen from above). (a) The data points $\left(50 \mathrm{~s}^{-1}\right)$ and the curve drawn through them. Arrows indicate the start and finish of the sequence, which comprises 3.5 cycles of beating. (b) The same as in (a), related to the notation for the increments in head angle shown in Fig. 7. p: pause; vr: very rapid; s: slow; r: rapid. (c) The same as in (a,b), related to the bending cycle and the times of maximal development of the principal $\left(P_{\max }\right)$ and reverse $\left(R_{\max }\right)$ bends. Scale bar represents $5 \mu \mathrm{m}$.

Evidence from mouse spermatozoa. For this purpose, spermatozoa were 'optically sectioned' as they 'swam', in a stable manner, vertically against the coverslip. The viscosity of the albumin-saline was not augmented and the recording was done at 200 'fields' $\mathrm{s}^{-1}$. By focusing on the sperm head (13 specimens), a net clockwise rotation (spin or roll) was easily visible. It was also evident that there were pauses in the rotation that were related to the beat cycle. This was analysed over 13 beat cycles of one of the most favourable specimens: measurement of the head angle at $5 \mathrm{~ms}$ intervals revealed the pattern in the rate of angular change to be: pause-very rapid-slowrapid-next pause. About half of the data set is shown (Fig. 7). There was often a slight anti-clockwise rotation during the 'pause' phase. From the out-of-focus image of the proximal flagellum, it was clear that this pattern (pause-very rapid-slow-rapid-next pause) was repeated at the frequency of the beat cycle. Focus was shifted down to a level approximately $15 \mu \mathrm{m}$ along the mid-piece and the position of the flagellum was plotted in successive frames to establish correspondence with the phases of the beat cycle (a different specimen was used, recorded with the strobe synchronized at $50 \mathrm{~Hz}$ to give brighter images). The resulting curve ('flagelloid' curve; Woolley, 1998) was easily constructed by interpolation and it too showed a succession of four phases repetitively: straight traversenarrow loop-curved traverse-wide loop (Fig. 8a). The straight traverse phase of the flagellar motion has no clockwise angular change and must therefore correspond to the 'pause' phase in the head movement. The phases of the flagelloid curve are thus equated with the pattern of head roll observed previously (Fig. 7) and have been labelled by the same 'pause-very rapid-slow-rapid-next pause' notation (Fig. 8b). It was then established which of the 'loops' of the curve correspond to the points of final development of the principal and reverse bends $\left(P_{\max }, R_{\max }\right)$. A few spermatozoa were studied in the same slide chamber, in lateral view, attached by a point on the anterior head (not illustrated but similar to that in Fig. 9). By plotting the side-to-side displacement of a point in the mid-piece, in successive frames (at 200 frames s$~^{-1}$ ), it was obvious that the time interval from $P_{\max }$ to $R_{\max }$ was shorter than that for the return stroke, $R_{\max }$ to $P_{\max }$. Analysis of the velocities around the flagelloid curve (proportional to the distance between successive points) indicated that the phase labelled ' $p$ ' in Fig. 8b must correspond to the slower of the two strokes of the flagellum, that is, from $R_{\max }$ to $P_{\max }$. The most rapid rotation (roll) of the head and proximal flagellum occurs at $P_{\max }$, continues at a lesser rate through $P_{\max }$ to $R_{\max }$ and increases again at $R_{\max }$ (Fig. 8c). In contrast, the $R_{\max }$ to $P_{\max }$ stroke of the flagellum is associated essentially with a pause or even a slight reversal of the rotation.

This deduction was confirmed by the behaviour of four spermatozoa observed in lateral view, tethered loosely near the neck by a strand of membrane such that the head was free to make a partial rotation. This angular motion of the head occurred during the $P_{\max }$ to $R_{\max }$ stroke of the proximal flagellum, and the head returned to its start position during the $R_{\max }$ to $P_{\max }$ movement (Fig. 9).

Evidence from chinchilla spermatozoa. Chinchilla spermatozoa were video-recorded in lateral view as they swam for brief periods adjacent to the coverslip. It was decided that the spermatozoa were rolling continuously clockwise, the reasoning being as follows. When the head turned edge-on to the observer, it could be seen to be inclined to the flagellar axis. Successive edge-on views showed an alternation in the angle of its inclination, whereas successive flat-on views showed an alternation in the surface of the head that was uppermost (Fig. 10). These observations indicate that the rolling of the head 
was continuous, not oscillatory. The direction of roll was deduced from the fact that only one surface of the head presented its anterior rim in sharp focus, meaning that its inclination was then upwards towards the surface of the coverslip. (This was the same surface as that uppermost in spermatozoa moving two-dimensionally.) Thus, successions of edge-on and flat-on views (Fig. 10) revealed that the roll was clockwise (as would be seen from ahead, that is, the same direction of roll as in mouse spermatozoa).

When these spermatozoa presented their heads 'edgeon', there was an oblique component to their forward movement, which is direct evidence that the head was acting as a hydrofoil (Fig. 10).

The demonstration that a torque was being applied intermittently to the head, during the faster of the flagellar 'strokes', was possible in several spermatozoa that were almost stabilized as two-dimensional (Fig. 11). After each application of torque the sperm head returned to its starting plane during the slower stroke, a movement very similar to that of the mouse spermatozoon in Fig. 9. The movement shown in Fig. 11 indicates that in the transition to the two-dimensional waveform, there is a phase during which the continuous roll of the cell is reduced to an oscillatory, rocking motion.

Evidence from ram spermatozoa. It was extremely rare to find ram spermatozoa positioned suitably for 'optical sectioning'. Three were found but for technical reasons the only conclusion that could be drawn was that the roll direction of the head (and flagellum) was clockwise (as for mouse and chinchilla). In addition, ten examples of oscillatory rocking were found: all were spermatozoa with very asymmetric bending and the turning of the head out of the plane was during the more rapid of the 'strokes' of the proximal flagellum (not shown as similar to Figs 9 and 11).

Movement at the surface when the flagellar wave is three-dimensional (various species)

Careful statistical analysis is required to determine whether spermatozoa accumulate at a surface. However, a reasonably sure judgement may be made if individual spermatozoa arrive at and then persistently swim beneath the coverslip. It is necessary to focus at only that level using a deep chamber and an objective of short focal depth.

Under this criterion both mouse and chinchilla spermatozoa, in physiological saline (no methyl cellulose), accumulate at the coverslip and swim there in clockwise circles. From their appearance, and from what has been described above, these spermatozoa spin as they progress. Thus, spermatozoa with a three-dimensional flagellar action and a spinning motion can be captured by a surface. Tracings were made of successive images so as to construct the whole-cell envelopes. Examples
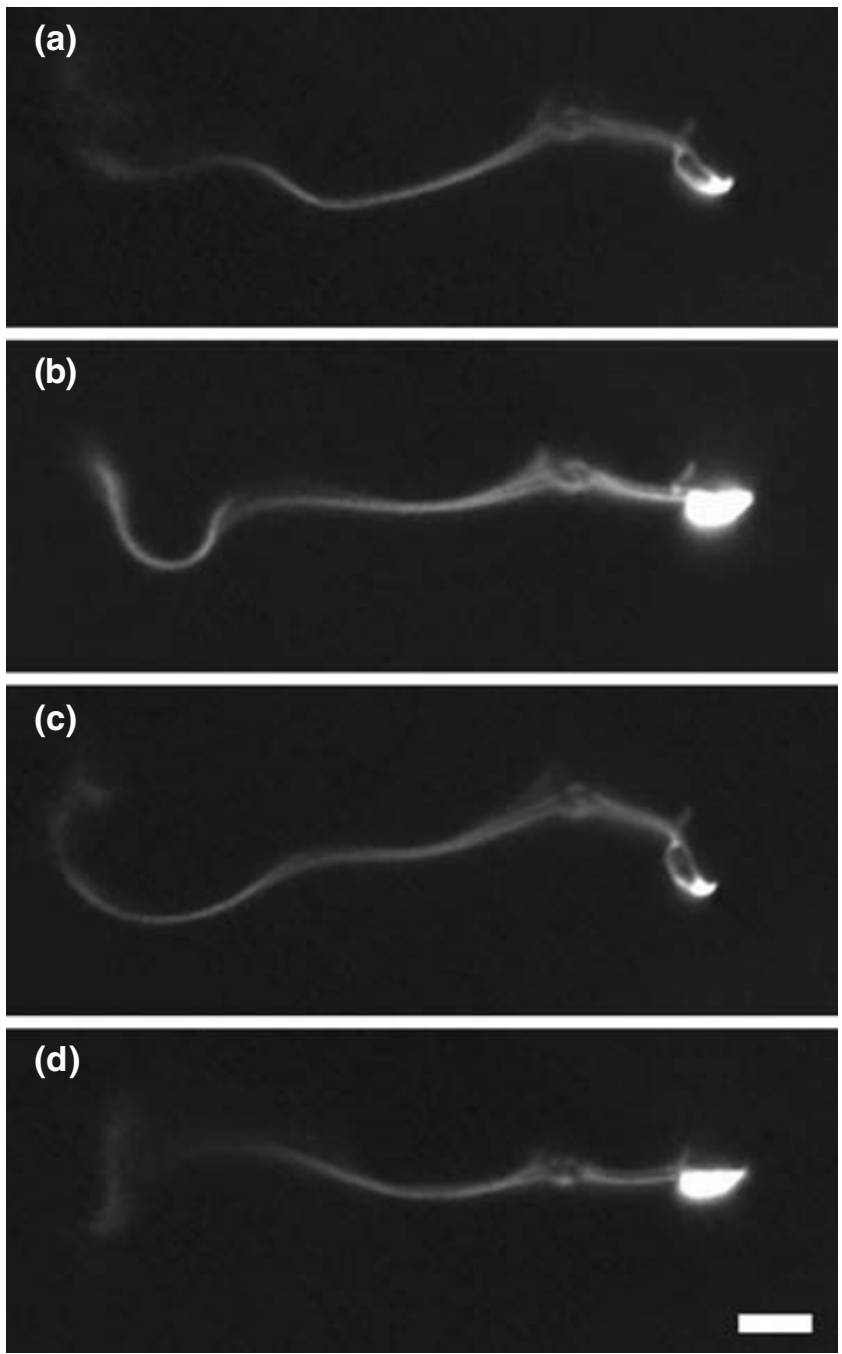

Fig. 9. A mouse spermatozoon 'swimming' in albumin-saline but loosely attached to the coverslip by a slip of membrane near the neck. Exposure time $8 \mu \mathrm{s}$. Two cycles of beating are represented. $(\mathrm{a}, \mathrm{c})$ The sperm head rolls back to lie in the plane of the surface as the flagellum returns from $R_{\max }$ to $P_{\max }$. (b, d) The sperm head rolls clockwise (as would be seen from ahead) as the proximal flagellum bends from $P_{\max }$ to $R_{\max }$. The observation supports the claim that a torque is applied to the head intermittently, in phase with the beat cycle and not during development of the principal $(\mathrm{P})$ bend. Scale bar represents $10 \mu \mathrm{m}$.

from chinchilla are shown (Fig. 12). The envelopes have a conical shape. The clockwise swimming paths are also shown (Fig. 13a,b).

The capture of various three-dimensional waveforms is a topic that had been overlooked in previous descriptions from our laboratory. Cockerel and starling spermatozoa tend to be captured and those that swim parallel to the coverslip for a time take clockwise paths (Fig. 13c,d). Xenopus spermatozoa too have clockwise paths against the coverslip (not shown). Eel spermatozoa are definitely captured by the coverslip and swim in anti-clockwise 

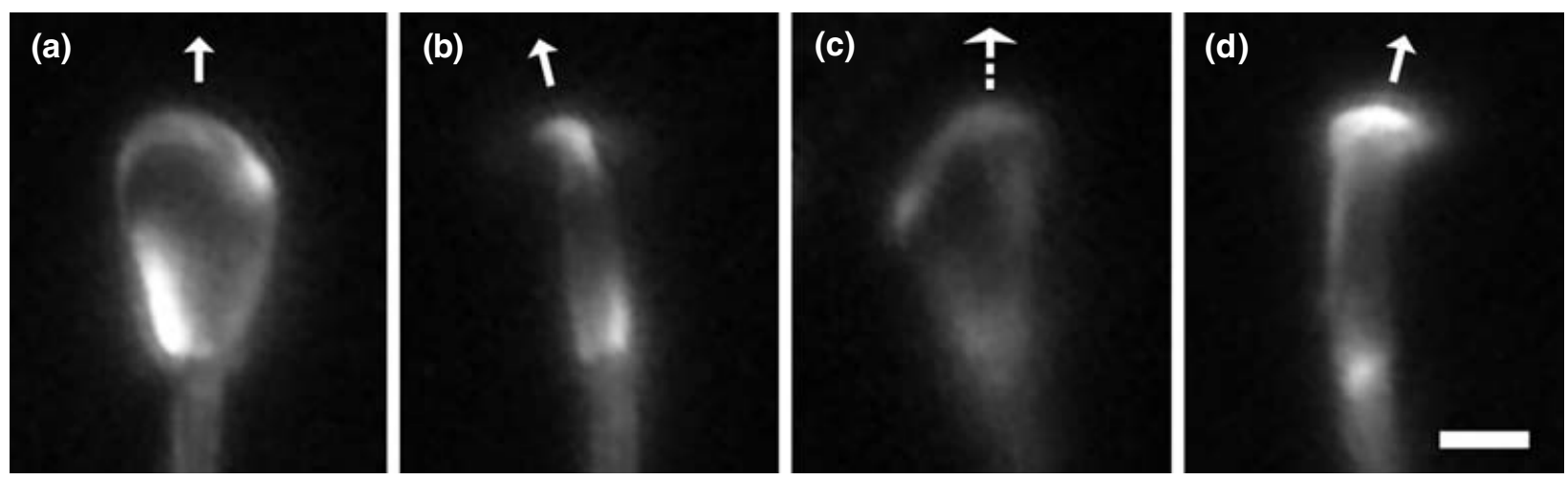

Fig. 10. A chinchilla spermatozoon during movement in viscous saline beneath the coverslip. Almost all such cells rolled continuously showing alternating aspects of the surfaces and edges of the sperm head. From the sequence of images, continuous clockwise roll can be deduced: (a) surface view, acrosome rim in focus; (b) $+90^{\circ}$ of roll, showing tilted orientation of head; (c) a further $90^{\circ}$ of roll showing opposite surface of head slightly out-of-focus; and (d) a further $90^{\circ}$ of roll. The cell moved forward during (a), whereas it moved forwards and slightly deeper in (c). It veered to the left during (b) and to the right during (d). Arrows indicate direction of movement. The hydrofoil action of the head was causing it to follow a sinistrally helical course. Scale bar represents $5 \mu \mathrm{m}$

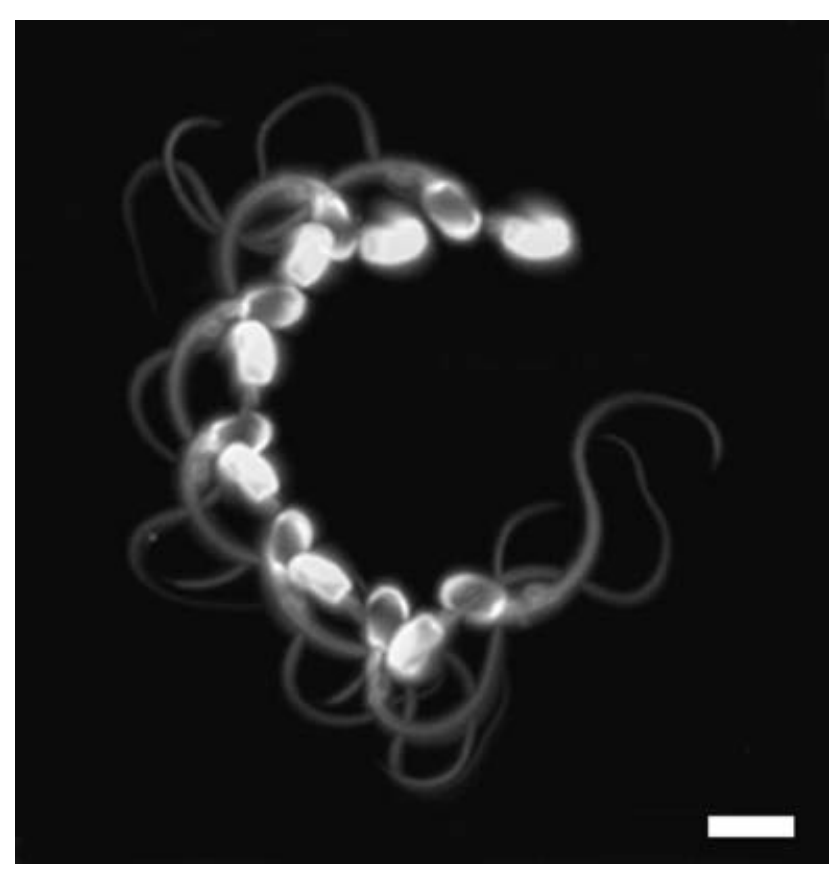

Fig. 11. Montage of images of a chinchilla spermatozoon swimming in viscous saline beneath the coverslip. The trajectory is a clockwise arc, with the flagellar wave essentially planar. Threedimensionality is not completely attenuated as a torque is regularly applied to the head during the more rapid of the alternating flagellar strokes, causing it to oscillate (rock) rather than achieve a continuous roll. Scale bar represents $20 \mu \mathrm{m}$.

circles (Fig. 13e). A simple pattern underlies the direction of circling in these collected observations. The circling behaviour depends on close proximity to the coverslip:
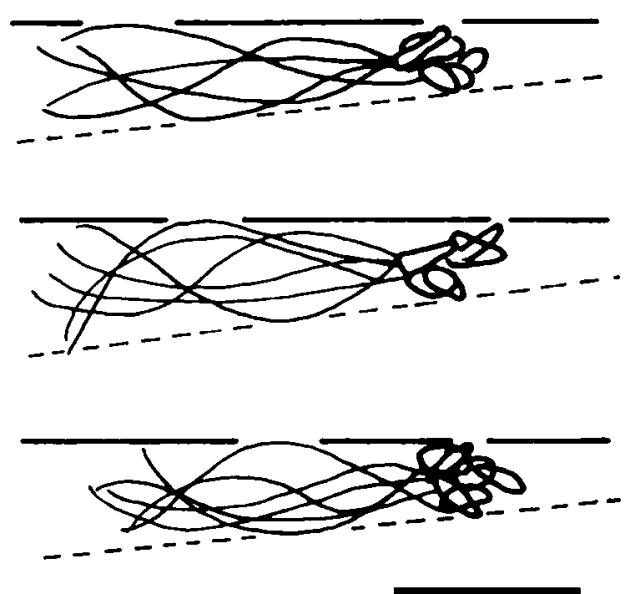

Fig. 12. Multiple superimposed tracings of individual chinchilla spermatozoa (swimming as in Fig. 13b) to suggest the envelope or swept-volume of the cell. The envelopes were drawn from above but, as they are symmetrical about the axis of rotation, they have been drawn here as if in side view, adjacent to a solid surface. These results indicate how the conical geometry will result in the cell achieving equilibrium such that the thrust from the fluid drives it towards the surface. Scale bar represents $25 \mu \mathrm{m}$.

for eel spermatozoa, the swimming trajectories became straight when the sperm were $20 \mu \mathrm{m}$ or more beneath the coverslip (or above the slide) (Fig. 13f). From the recordings of eel spermatozoa, it was also possible to estimate the roll frequency of the cells, as well as their curvilinear velocity. The curvature of the trajectory at the coverslip was correlated with velocity $(r=0.44$, $P<0.02)$ but was more closely correlated with roll frequency/velocity $(r=-0.53, P<0.01)$ (Fig. 14). 

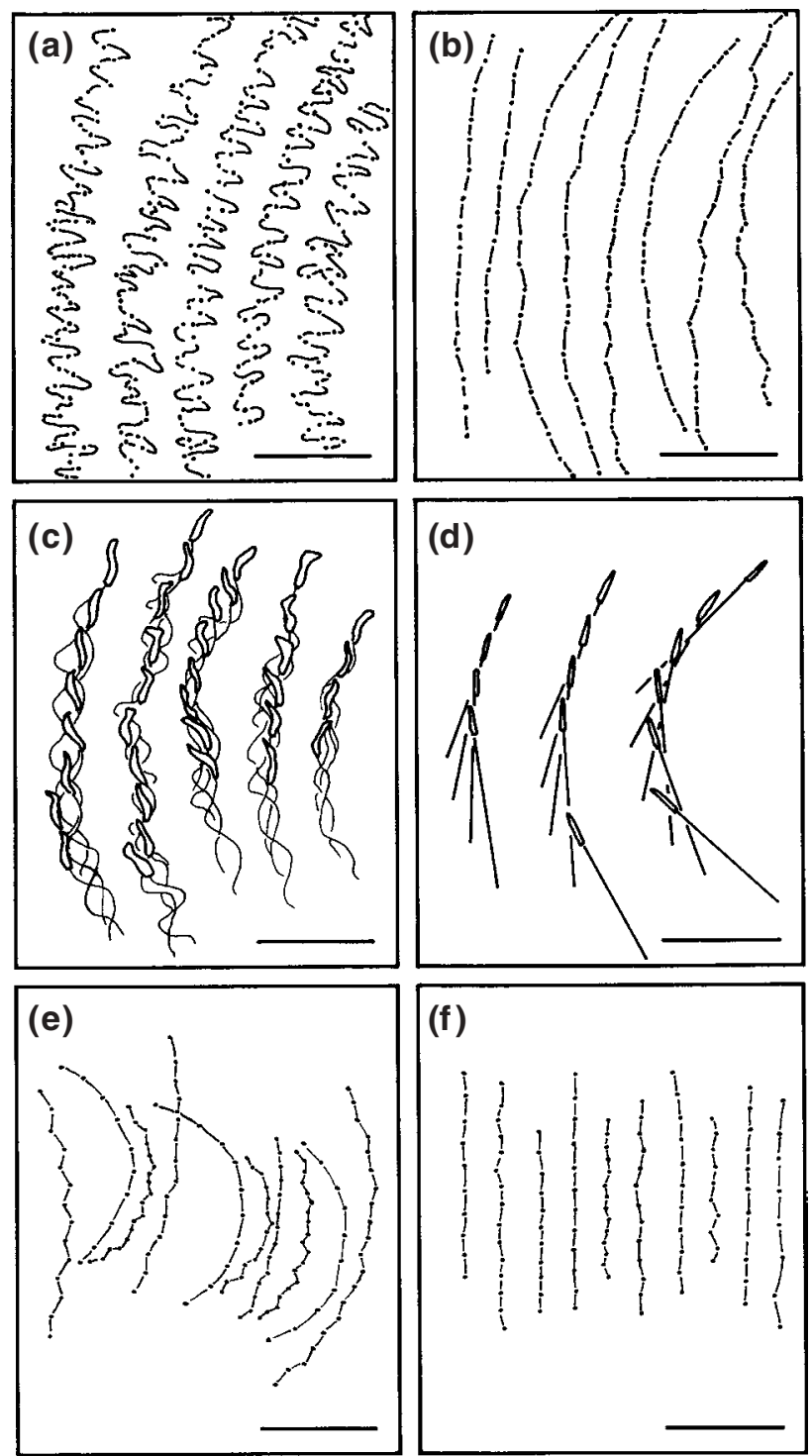

Fig. 13. Representative trajectories of spermatozoa, with threedimensional waveforms and rolling motion, swimming adjacent to the coverslip in albumin-saline (except in (f)). The trajectories are arranged in each figure with spermatozoa moving towards the top of the frame. (a) Mouse spermatozoa: sperm head position plotted every $60 \mathrm{~ms}$; an equal number of spermatozoa (data not shown) swam in essentially straight trajections. (b) Chinchilla spermatozoa: head positions plotted every 200 ms. (c) Cockerel spermatozoa, drawn at convenient intervals: the sperm head tracings are variable because of depth variation; the helical waveforms are drawn approximately as two-dimensional projections. (d) Starling spermatozoa: entire spermatozoa drawn at convenient intervals to illustrate the 'twist-drill' waveform. (e) Eel spermatozoa: head positions plotted every $100 \mathrm{~ms}$. (f) Eel spermatozoa: representing spermatozoa swimming $20 \mu \mathrm{m}$ below the coverslip; at depths of $7 \mu \mathrm{m}$ and $13 \mu \mathrm{m}$ the curvature of the paths was pronounced and just detectable, respectively (data not shown); the depths quoted are actual not apparent. Scale bars represent $50 \mu \mathrm{m}$.

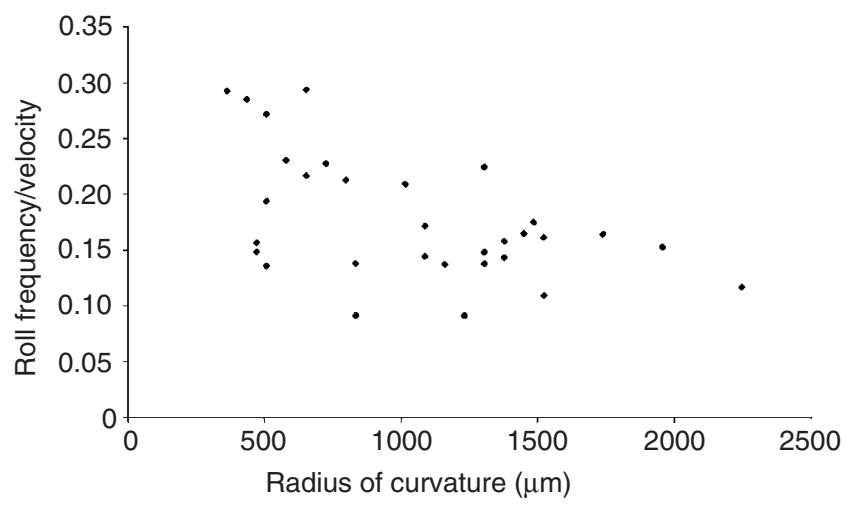

Fig. 14. The relationship between curvilinear velocity $(U)$, roll frequency $(\Omega)$ and radius of curvature of trajectory for eel spermatozoa, using 31 specimens of the type illustrated in Fig. 13e. There was a significant negative correlation between $U / \Omega$ and the radius of curvature.

\section{Discussion}

When a spermatozoon swims close to a solid boundary the motions it generates in the fluid are constrained by the surface. The 'wall effect' is complex, in part because the potential for increased active thrust is constrained by increased passive resistance to the movement of the head (Katz and Blake, 1975; Katz et al., 1989). One aspect of the wall effect can be a tendency for the spermatozoa to remain at the surface, which is the long recognized 'capturing' phenomenon described by Dewitz (1886) and first quantified by Rothschild (1963) for bull spermatozoa. Various aspects of this 'capture' have not been satisfactorily explained. As a starting point, a basic distinction between 'capture as a two-dimensional waveform' and 'capture as a threedimensional waveform' must be emphasized.

Thus, how spermatozoa swimming two-dimensionally come to be trapped will first be discussed. The key phenomenon is the 'left-hand rule' for mouse spermatozoa, which depends on the normal structure, attachment and orientation of the sperm head. The same rule applies to rat, chinchilla and ram spermatozoa. The proposed explanation for this 'rule' is that the head is acting as a hydrofoil. This possibility is suggested by the scanning electron micrographs (mouse) and is demonstrated directly by the systematic deflections in swimming path (chinchilla). The tilted orientation of the head in chinchilla spermatozoa may be seen in an electron micrograph of Fawcett and Phillips (1969). Evidence that an asymmetric head insertion can have a 'steering' action on sperm movement was provided by Goldstein (1977). From the results of the present study, it is proposed that the sperm head, acting as a hydrofoil, will in one orientation come to exert a pressure against the surface. This could have adaptive significance in directing the thrust of the spermatozoon into the substance of the zona pellucida (rather then parallel to 
it), thereby producing the well-known oblique incision (Yanagimachi, 1994).

Therefore, a hydrofoil effect could explain bias in the direction of circling of spermatozoa with twodimensional waveforms at surfaces. The circling per se is the outcome of the beat asymmetry (Rikmenspoel et al., 1960; Keller and Rubinow, 1976; Goldstein, 1977). However, the cause of the direction of the circling has been an unsolved problem. Now it is clear that if only one surface of the head will stabilize against the surface, circling of uniform direction will occur if the beat is asymmetrical in a standard way. Unidirectional (or strongly biased) circling has long been described, for example in sea urchin spermatozoa (Dungern, 1901; Buller, 1902), but it has been given a different explanation: namely, that a helical path has been compressed into a circular path and has retained its original chirality (Buller, 1902; Brokaw, 1974; Ishijima and Hamaguchi; 1992; Ishijima and Hamaguchi; 1993). However, the chirality of the helical path has not been ascertained.

An alternative explanation for the capture of twodimensional sperm waveforms (sea urchin, fish) has recently been proposed by Cosson et al. (2003). These authors believe that the apparently two-dimensional waves actually deviate from planarity such that, if viewed from in front, the flagellum has a figure-of-eight course, very compressed in amplitude but sufficient for each travelling bend to elicit lift as well as thrust. The shape strongly resembles the sea urchin waveforms described as quasi-planar by Woolley and Vernon (2001).

Capture as a two-dimensional wave involves loss of three-dimensionality in the flagellar motion. This transformation will now be discussed for mammalian spermatozoa. It will not be necessary to postulate a helical-to-planar switch in the flagellar motor. (A switch of that type occurs in sea urchin spermatozoa, unrelated to contact with surfaces, and also in quail spermatozoa on contact with a surface; Woolley and Vernon, 1999, 2001.) There is no need for an either/or type of switch if the three-dimensional wave in mammals is interpreted not as helical but as 'twisted planar', with the 'twist' component suppressible in some circumstances. These descriptions revive an old controversy. Some investigators have judged the wave to be elliptically helical (Rikmenspoel, 1965; Denehy et al., 1975; Ishijima et al., 1986; Ishijima and Witman, 1987); other workers have claimed that it is a 'plane' wave that has localized torsions (Gray, 1958; Blokhuis, 1961; David et al., 1981) with the torsions characteristic of interbend regions of the wave (Woolley, 1977; Woolley and Osborn, 1984). (The 'planar' wave of the sea urchin spermatozoa can also develop localized inter-bend torsions (Murray, 1986; Woolley and Vernon, 2001)). If the wave on the mammalian sperm flagellum were elliptically helical, the entire cell would roll in the direction contrary to the angular motion of the helically moving flagellum. This rotation/counter-rotation has not been demonstrated.
The findings of the present study support a 'twisted planar' rather than a helical interpretation of the wave. The key observation is the pause in the roll of the head during each beat cycle of the flagellum, with sometimes a slight reversal of the roll during the pause; this should not occur with an elliptically helical wave because a helical motion would elicit a continuous counter-rotation. In the 'twisted planar' interpretation of the wave there is an actively generated torsion in a localized region of the flagellum. This will exert torques of equal magnitude but opposite direction on the flagellar regions proximal and distal to the torsion. The opposing torques from the fluid will therefore be in balance and no wholecell roll will be established. The effect of two torques would be to change the shape of the cell. However, the angular movement of the two parts proximal and distal to the torsion, in relation to external co-ordinates, will not be the same if, for geometrical reasons, they experience differential resistance from the fluid. Thus, for a mammalian spermatozoon, developing a sinistral torsion actively in the most proximal part of the flagellum, it is the sperm head that will turn most relative to external co-ordinates; and in doing so, it will carry the base of the flagellum clockwise and establish the succeeding bend in a plane that is twisted relative to the preceding one.

In mouse spermatozoa, the active torsions occur in the intervals between the flagellar strokes and also during the stroke $P_{\max }$ to $R_{\max }$, producing about $150^{\circ}$ of roll per beat cycle. It is emphasized that none of this roll occurs during one of the flagellar strokes (that is, from $R_{\max }$ to $P_{\max }$ ). This description agrees well with that given for mouse spermatozoa by Phillips (1972), in which he described $180^{\circ}$ of rotation occurring during alternate strokes of the flagellum. Such large deflections explain in a general way the complexity of the entire waveform in free-swimming mouse spermatozoa (Woolley et al., 1983). In addition, when spermatozoa are free swimming, angled surfaces on the edges of the sperm head will affect the degree of roll during the flagellar strokes. The angulation of the hook on rat and mouse spermatozoa heads is in the right direction to accentuate the angular deflection during the $P_{\max }$ to $R_{\max }$ stroke.

An increase in viscosity is one factor that suppresses the torsion and renders the wave two-dimensional. A viscosity effect has been reported for spermatozoa in cervical mucus by Gaddum-Rosse et al. (1980) and has now been confirmed for rat and mouse spermatozoa using methyl cellulose solutions. In addition, the solid surface itself will be an impediment to this turning movement of the head, as has commonly been supposed. Holding the head in a micropipette would also be expected to suppress three-dimensionality, giving essentially planar waves (as shown by Ishijima and Mohri, 1985; Ishijima et al., 1986; Ishijima and Witman, 1987). Spermatozoa with a lengthy hook extending from the head (for example, rat), when swimming very close to a solid boundary, will need to generate a greater torque to 
Table 1. A comparison of various spermatozoa with three-dimensional waveforms, relating roll direction to circling direction

\begin{tabular}{|c|c|c|c|}
\hline Species & $\begin{array}{l}\text { Type of three-dimensional } \\
\text { waveform }\end{array}$ & Roll direction* & Circling direction $^{\dagger}$ \\
\hline Sea urchin & Helical $^{\mathrm{a}}$ & Clockwise $^{a}$ & Clockwise $^{\mathrm{a}}$ \\
\hline Eel & Helicalc & Anti-clockwise ${ }^{\mathrm{c}}$ & Anti-clockwise ${ }^{b}$ \\
\hline Domestic fowl & Helical $^{d}$ & Clockwise $^{d}$ & Clockwise $^{b}$ \\
\hline Starling & Helical $^{\mathrm{d}}$ (inferred) & Clockwise $^{d}$ & Clockwise $^{b}$ \\
\hline Xenopus & Unknown & Clockwise $^{\mathrm{e}}$ & Clockwise $^{b}$ \\
\hline Mouse & Twisted planar ${ }^{b}$ & Clockwise $^{b}$ & Clockwise $^{b}$ \\
\hline Chinchilla & Twisted planar ${ }^{b}$ & Clockwise $^{b}$ & Clockwise $^{b}$ \\
\hline
\end{tabular}

*As seen from in front of the sperm head.

${ }^{\dagger}$ At coverslip, seen from above (no conversion to two-dimensionality).

aWoolley and Vernon (2001).

${ }^{\mathrm{b}}$ Reported in present paper.

cWoolley (1998).

${ }^{\mathrm{d}}$ Vernon and Woolley (1999).

e D. M. Woolley (unpublished).

complete the roll of the head from left-surface-to-rightsurface than contrariwise, and this probably affects the orientation in which they stabilize. When the torque becomes severely attenuated, the head turns through only a small angle and there is time for it to roll back. This finding implies that there is an internal elastic resistance to the torsion. This phenomenon may account for reports that human spermatozoa can oscillate rather than roll continuously (Zorgniotti et al., 1958).

These three-dimensional movements have been of interest mainly because they may reveal fundamental aspects of ciliary and flagellar function. For example, the ciliary effective stroke is planar but in the recovery stroke of most cilia the cilium turns away from this plane, becoming three-dimensional (for a review, see Machemer, 1977). There is a broad similarity to what has been described above: it may repay further examination. If the twisted plane scheme is indeed an indication of fundamental phenomena, one would expect some uniformity in the chirality of the torsion and hence the roll direction of mammalian spermatozoa. In the four mammals studied here, the roll of the cell has always been clockwise (seen from ahead). The most reliable reports are based on spermatozoa 'swimming' upwards or downwards, loosely attached to the glass. However, even by this method of judgement there is no further uniformity between species reported in the literature and, in some species, both roll directions have been reported (for reviews, see Woolley, 1979 and Ishijima et al., 1992).

It is proposed that the capture of three-dimensional waveforms occurs when the envelope of the wave is conical. With this shape the cell can stabilize at an interface only when the side of the cone lies parallel to that surface and, in this orientation, the direction of thrust will always drive the head obliquely towards the surface. Contact with the surface will presumably further restrict the amplitude of head movements. When the surface is a solid- rather than an air-interface, the spinning motion of the head very close to the no-slip zone (Shapiro, 1964) must result in a net lateral force from the fluid, causing the cell to deviate from a straight trajectory to a circular one. The direction of circling (at the coverslip, seen from above) would be expected to be the same as the direction in which the cell rolls or spins (seen from ahead), and this is what has been found (Table 1). For the twisted planar wave, the flagellum turns in the same direction as the head and elicits an additional lateral force; this should generate a track with a relatively large radius of curvature. For a truly helical wave, the flagellum has a net angular velocity in the direction opposite to that of the head and would be expected to cause the rear of the cell to be deflected oppositely to the head, causing the cell to follow a circular track of relatively small radius. The effect of proximity-to-the-surface on path curvature was lost at a distance of $20 \mu \mathrm{m}$. This result is consistent with the theoretical estimate for the range of the wall effect (Katz et al., 1989). The results to date (Table 1) show that an easy way to decide the roll direction of a spermatozoon is to observe its circling direction.

The author would like to express his thanks to M. Holwill for helpful discussions, to N. Cooper and I. Thomas for some of the material, to Geraint Vernon for preparing the illustrations; to R. Porter for the scanning electron microscopy, and to G. Tilly and D. Carter for technical assistance. The research has been undertaken with the financial help of BBSRC (UK), grant no. 7/C11957.

\section{References}

Bernardini G, Andrietti F, Canatini M and Cosson MP (1988) Xenopus spermatozoon: correlation between shape and motility Gamete Research $\mathbf{2 0}$ 165-175

Blokhuis EWM (1961) Optical investigations on the movement of bull spermatozoa Proceedings of the IV International Congress on Animal Reproduction 2 243-248 
Brokaw CJ (1974) Movement of the flagellum of some marine invertebrate spermatozoa. In Cilia and Flagella pp 93-109 Ed. MA Sleigh. Academic Press, London and New York

Buller AHR (1902) Is chemotaxis a factor in the fertilization of the eggs of animals? Quarterly Journal of Microscopical Science 46 145-176

Cosson J, Huitorel P and Gagnon C (2003) How spermatozoa come to be confined to surfaces Cell Motility and the Cytoskeleton 54 56-63

David G, Serres C and Jouannet P (1981) Kinematics of human spermatozoa Gamete Research 4 83-95

Denehy MA, Herbison-Evans D and Denehy BV (1975) Rotational and oscillatory components of the tailwave in ram spermatozoa Biology of Reproduction 13 289-297

Dewitz J (1886) Ueber Gesetzmässigkeit in der Ortsveränderung der Spermatozoen und in der vereinigung derselben mit dem Ei Archiv für der Gesellschaft Physiologisch 38 358-385

Dungern FV (1901) Cited by Marshall FHA (1910) The Physiology of Reproduction (First Edition). Longmans Green \& Co., London

Fawcett DW and Phillips DM (1969) Observations on the release of spermatozoa and on changes in the head during passage through the epididymis Journal of Reproduction and Fertility Supplement 6 405-418

Friend CF (1936) The sperms of the British Muridae Quarterly Journal of Microscopical Science $\mathbf{7 8} 419-443$

Gaddum-Rosse P, Blandau RJ and Lee WI (1980) Sperm penetration into cervical mucus in vitro. I. Comparative studies Fertility and Sterility 33 636-643

Goldstein SF (1977) Asymmetric waveforms in Echinoderm sperm flagella Journal of Experimental Biology 71 157-170

Gray J (1958) The movement of the spermatozoa of the bull Journal of Experimental Biology 35 96-108

Ishijima S and Hamaguchi Y (1992) Relationship between direction of rolling and yawing of golden hamster and sea urchin spermatozoa Cell Structure and Function 17 319-323

Ishijima S and Hamaguchi Y (1993) Calcium ion regulation of chirality of beating flagellum of reactivated sea urchin spermatozoa Biophysical Journal 65 1445-1448

Ishijima S and Mohri H (1985) A quantitative description of flagellar movement in golden hamster spermatozoa Journal of Experimental Biology 114 463-475

Ishijima S and Witman GB (1987) Flagellar movement in intact and demembranated, reactivated ram spermatozoa Cell Motility and the Cytoskeleton 8 375-391

Ishijima S, Oshio S and Mohri H (1986) Flagellar movement of human spermatozoa Gamete Research 13 185-197

Ishijima S, Hamaguchi MS, Naruse M, Ishijima SA and Hamaguchi Y (1992) Rotational movement of a spermatozoon around its long axis Journal of Experimental Biology 163 15-31

Katz DF and Blake JR (1975) Flagellar motion near walls. In Swimming and Flying in Nature pp 173-184 Eds TY Wu and CJ Brokaw. Plenum Press, New York

Katz DF, Drobnis EZ and Overstreet JW (1989) Factors regulating mammalian sperm migration through the female reproductive tract and oocyte investments Gamete Research 22 443-469

Keller JB and Rubinov SI (1976) Swimming of flagellated microorganisms Biophysical Journal 16 151-170
Machemer H (1977) Motor activity and bioelectric control of cilia Fortschritte der Zoologie 24 195-210

Murray JM (1986) Electron microscopy of frozen hydrated enkaryotic flagella Journal of Ultrastructure and Molecular Structure Research 95 196-209

Phillips DM (1972) Comparative analysis of mammalian sperm motility Journal of Cell Biology 53 561-573

Retzius G (1909) Die spermien der Nagetiere Biologische Untersuchungen, Neue Folge 14 153-156

Rikmenspoel R (1965) The tail movement of bull spermatozoa. Observations and model calculations Biophysical Journal 5 365-392

Rikmenspoel R, Van Herpen G and Eijkhout P (1960) Cinematographic observations of the movements of bull sperm cells Physics in Medicine and Biology 5 167-181

Rothschild Lord (1953) The movements of spermatozoa. In Mammalian Germ Cells pp 122-133 CIBA Foundation Symposium Ed. GEW Wolstenholme. Churchill Ltd, London

Rothschild Lord (1963) Non-random distribution of bull spermatozoa in a drop of sperm suspension Nature London 198 1221-1222

Shapiro AH (1964) Shape and Flow: The Fluid Dynamics of Drag Heinemann, London

Vernon GG and Woolley DM (1999) Three-dimensional motion of avian spermatozoa Cell Motility and the Cytoskeleton 42 149-161

Woolley DM (1977) Evidence for "twisted plane" undulations in golden hamster sperm tails Journal of Cell Biology 75 851-865

Woolley DM (1979) Interpretations of the pattern of sperm tail movements. In The Spermatozoon pp 69-79 Eds DW Fawcett and JM Bedford. Urban and Schwarzenberg, Baltimore and Munich

Woolley DM (1997) Studies on the eel sperm flagellum. I. The structure of the inner dynein arm complex Journal of Cell Science 110 85-94

Woolley DM (1998) Studies on the eel sperm flagellum. II. The kinematics of normal motility Cell Motility and the Cytoskeleton 39 233-245

Woolley DM and Osborn IW (1984) Three-dimensional geometry of motile hamster spermatozoa Journal of Cell Science 67 159-170

Woolley DM and Vernon GG (1999) Alternating torsions in a living ' $9+2$ ' flagellum Proceedings of the Royal Society of London B 266 1271-1275

Woolley DM and Vernon GG (2001) A study of helical and planar waves on sea urchin sperm flagella, with a theory of how they are generated Journal of Experimental Biology 204 1333-1345

Woolley DM, Osborn IW, Oliver EJH and Rea DW (1983) Observation of the tailwaves of mouse spermatozoa. In The Sperm Cell pp 356-359 Ed. J André. Matinus Nijhoff, The Hague

Yanagimachi R (1994) Mammalian fertilization. In The Physiology of Reproduction pp 189-317 Eds E Knobil et al. Raven Press, New York

Zorgniotti AW, Hotchkiss RS and Wall LC (1958) High speed cinephotomicrography of human spermatozoa Medical Radiography and Photography 34 44-49

Received 16 January 2003.

First decision 10 March 2003.

Revised manuscript received 24 March 2003.

Accepted 26 March 2003. 